\title{
Study on Improving Democratic Appraisal System of Chinese Party and Government Leaders: the 360-Degree Feedback based on Competency Model
}

\author{
Bai Yang ${ }^{1}$, Li Yongkang ${ }^{2}$, Wang Junjie ${ }^{1}$ \\ ${ }^{1}$ School of Public Administration and Policy, Renmin University of China, Beijing, P.R. China, \\ 100872 \\ ${ }^{2}$ School of Public Management, Yunnan University of Economics and Finance, \\ Kunming, P.R. China, 650221 \\ (E-mail: byking1985@163.com,LYK@163.com,wangjunjie268@163.com)
}

\begin{abstract}
The article adopted literature research, case study and comparative study methods aiming at discussing the fundamental path to complement and improve democratic appraisal system (DAS) -based on its existing practice-and the future development. We made careful study on the achievement and deficits of DAS for Chinese party and government leaders (PGLs) and the relationship among DAS, 360-degree feedback and competency model. This paper put forward the hypothesis that since the DAS is similar in process with 360-degree feedback and in content with competency model, there would be possibility to introduce both the two tools of 360-degree feedback and competency model into the DAS. By building competency model based 360-degree feedback system, we concluded that it is of great value in evaluating the person to be assessed thoroughly and accurately as well as facilitating his/her ability development. We also tried hard to carry out empirical study with field sample data.
\end{abstract}

Keywords: Competency Model, 360-Degree Feedback, Party and Government Leaders, Democratic Appraisal System

\section{Introduction}

Resent years, democratic appraisal system (DAS) has become an absolutely necessary and important procedure in activities such as the government executives' selection, annual assessment and executive team election etc. Department of the central committee of the communist party emphasized the important significance of DAS for optimizing scientific cadre selection mechanism and supervision and management mechanism, advancing the cadre of work scientific, democratic, institutional in several system and its complete refining files such as The party and government leaders selection regulations(2002) and The local party and government leading team and leaders' comprehensive evaluation method that requires to reflect the scientific development value(2006). In practice, the implication of DAS also plays an import role in seeking public opinion, appraising cadres accurately and promoting the diligence and probity of leading cadres. However, there are deficits in content design, tool refinement and appraisal results application of the DAS, this paper aims at discussing how to optimize and improve DAS of leaders in China based on related theories and practices of competency model and 360-degree feedback in modern human resource management.

\section{Comments on the connotation and present situation of DAS for Chinese Party and Government leaders}

\subsection{The connotation and application of DAS}

The party and government leaders (PGLs) are persons who lead responsibility in China's Party and Government organs at all levels. In General, apart from party and country leaders, people who are in leadership positions in party committees and government agencies at the local township level above belong to the PGLs. 
The PGLs are the backbone of the party and the government; they play the role of policy makers, organizers and leaders in the implementation of the party and government' routes, principles and policies. Their characteristics, cultivation and work state have been of great influence to the party and the government's governing ability and level. Therefore, the party and the government concerned a lot about the leader team construction and make great efforts to take a variety of different measures to ensure selecting high quality and qualified PGLs. Moreover, they ensure PGLs who get the appointment reaching a good job performance through comprehensive evaluation and assessment method. DAS is an important tool for public evaluation of the PGLs' moral and talent status as well as actual achievements. Whether it is in terms of selecting and appointing of PGLs, or it is in the comprehensive evaluation as well as the annual assessment, democratic appraisal methods are widely used. Generally speaking, DAS Democratic in the selection and appointment of leaders has become an indispensable tool and is playing an important role.

\subsection{The achievements and main problems of DAS}

The achievements of establishing DAS rely on two aspects: one is that it helps the party and the government evaluating the PGLs and their candidates more comprehensively and accurately in ethics (De), ability (Neng), diligence (Qin), performance (Ji), probity (Lian), the five aspects of their performance and the actual work performance. Compared to the old method, the DAS is more scientific in the way of selection, appointment and evaluation. So it contributes to make personnel decisions much more accurately and effectively. On the other hand, DAS is an important manifestation of adhering to the party's mass line in personnel work. It increases the participation of the cadres and the masses in the HR decisions of the PGLs' selection, appointment and appraisal. The DAS not only helps improving the satisfaction and acceptance of the cadres and the masses to personnel decisions making by the party and government organizations, but also helps to bring into play the party members and cadres' function of supervision for PGLs. At last, it's very positive meaning for DAS to supervise the leaders of incorrupt, self-discipline, strict demands on themselves and to do all the work consciously.

Undeniably, there are some defects in today's DAS. These defects not only affect the normal functioning of democratic appraisal tools, but also caused some of the cadres and the masses have a doubt on the effectiveness of DAS. In general, there are four deficiencies in DAS currently:

1. DAS mix the ability evaluation and performance appraisal;

2. The standards of DAS are fuzzy, disunity and lack of observable behaviors definition;

3. The index system of DAS classifies in confusion and lacks of logic;

4. The problem in evaluators' selection.

At present the DAS in the assessment of leaders is no consensus in the contents of basic concept, mechanism, and operational principle and implementation steps. In theory, it lacks a wide range, strong persuasive, generally accepted evaluation model. Therefore, we need to further research to improve and optimize the democratic appraisal system for leaders.

\section{The basic principle and application of 360-degree feedback and competency model}

\subsection{0-degree feedback}

Since the 1990s, 360-degree feedback program has been not only in the private sector, and in the public sector also widely applied. Pushed by the new public administration movement, the United States, Britain and many other countries are in the implementation of the plan in government agencies. 360-degree feedback is that a member of the organization at the same time receives evaluation and information feedback from the following aspects: direct superiors, subordinates, and colleagues at the same level or himself. Sometimes, customers from outside the organization or suppliers may also be invited to participate as evaluators. From the specific operational point of view, the HR department often prior to design a questionnaire which including evaluation indicators and grading standards, then let the stakeholders associated with the person to be evaluated appraise his/her work behavior, ability or the results that created from these abilities or behaviors. The organization always feedback the results to the relate people in order to improve their work behaviors, abilities 
or performance by accepting the information and making development plan. Most researchers have suggested, in many cases, 360 - feedback is best to just be used for development purposes, rather than all at once for performance appraisal purposes, so as to improve the accuracy of the feedback(Liu, 2009).

\subsection{Competency model}

A competency model is a descriptive tool that identifies the competencies needed to operate in a specific role within a(n) job, occupation, organization, or industry. Simply stated, a competency model is a behavioral job description that must be defined by each occupational function and each job (Fogg, 1999). Depending on the work and organizational environment, a group of 7 to 9 total competencies are usually required of a particular job and depicted in a competency model (Shippman, et. al., 2000). Dubois (2004) in defining competency models states that they provide the adhesion or "glue" that is necessary among the elements of an organizations human resource management system. It means that competency models help organizations take a unified and coordinated approach to designing the human resource management system, including job designs, hiring, performance management, employee development, career planning or succession planning and compensation system. In 2005, Hewitt Associates studied leadership development among 373 U.S. companies, 20 of which were labeled "Top 20 Companies for Leaders." The standout companies for leaders not only all have leadership competencies in place, but successfully integrate the competencies into succession planning, pay formulas, and performance management. The results collected in the study showed the percentile companies that measured leader performance against competencies, Top20 was $95 \%$ and the other was $69 \%$ (Vazirani, 2010). In addition, competency theory and method is also widely used in the public sector such as the United States, Canada, Australia, and European countries, having one after another into the competency movement.

\subsection{The relationship between 360 -degree feedback and competency model}

In the past years of the exploration for $360^{\circ}$ feedback's evaluation structure, whether design evaluation structure based on competency model, how to select and define the factors construction of the competency model has been the focus of the study of the issue. Early stages, people tended to design evaluation structure elements with more haphazard; however, practical experience shows that in order to play the role of 360-degree feedback much better, we need to have the appropriate feedback and problem-solving methods such as training, personal development plans which must be based on a reference platform for each other (Shi,2002). Edwards \&Ewen suggested structuring 360-degree feedback questionnaire based on competency model. Although competencies can't be used as assessment indicators directly, they have a direct link with all kinds of management indicators. So we can create related behavioral indicators with the help of competency model.

Many organizations have started to introduce competencies into training development project with $360{ }^{\circ}$ feedback questionnaires. Therefore, $360^{\circ}$ feedback and competency models are more and more closely linked together, especially when they are used for training and development system. Because the organization hopes to ensure that their concerns on ability are correct. Competent for competency model shows the most relevant behavior of the performance, and $360^{\circ}$ feedback is discussed in detail what the behaviors need in work. If taken in combination, it would help to identify which part needs development to improve job performance.

\section{The path to optimize DAS for Chinese party and government leaders in future}

\subsection{DAS, $360^{\circ}$ feedback and competency model}

Competency model is a series of important characteristics which is basis for the excellent performance. The model contributes refining and optimizing content of DAS. $360^{\circ}$ feedback is a kind of evaluation method applying in the process of DAS. Although current DAS is similar to $360^{\circ}$ feedback, it is give priority to assessment instead of feedback. The relationship between the three management tools as follows: 
There are seven competencies that belong to managers of China's public department, including political quality, leadership, Man-Oriented, coordination, self-discipline, learning ability, working ability (Wang, Cui, 2006). DAS as an appraisal method for evaluating behavior and performance of managers in public sectors, the content and the elements embodies the thought of manager competency model. For example, political attitude and thought quality in "ethic" corresponding characteristics of "political quality" dimension; the "working ideas" "psychological characteristics" "spirit status" and "leadership" corresponding "Organization alliance" and "coordination ability" consistently; "In accordance with the law" "incorrupt and self-discipline" corresponding "self-discipline"; "work effect" "solving complex problems" "infrastructure" corresponding "work ability".

Except the person to be assessed not doing self-evaluation, DAS and $360^{\circ}$ feedback is very similar. It's an effective form of multi-collecting public opinion, judging cadres objectively, fairly and accurately, and proceeding cadres' performance feedback in the public sector ( $\mathrm{Li}, \mathrm{Yu}, 1998)$. But it is worth noting that DAS is based on working report, and the report itself is the evaluation and summary of self-performance in the performance cycle. So, we can consider that the information sources of the DAS and $360^{\circ}$ feedback are nearly the same.

From the analysis above, we can see that the content and evaluation process of DAS are similar and connected with competency model and $360^{\circ}$ feedback. So introducing the two human resources management tools into DAS are feasible.

\subsection{The values for implementing $360^{\circ}$ feedback system based on competency model in DAS}

4.2.1. Provide by evaluation's work behavior information for evaluators comprehensively

As we mentioned above, democratic assessment system had defect that the evaluators lack enough information to assess and monitor performance effectively and precisely. The evaluation system emphasizes on measuring what have accomplished at work, and pays little attention to how they accomplish the work. The evaluation based on competencies with the behavior of concrete example to measure the ability and performance of cadres, make sure that their achievements as well as the realization of the achievement would be examined. A well-structured model could help focusing on key behaviors related to success performance; and the evaluator and the cadres are more likely to treat DAS seriously and are willing to invest time and energy to form development plans and improvement suggestion. Competency model can determine which behaviors are important to improve performance, so it provides a starting point for democratic assessment. If we assumed "leadership" was the key competency, then we could search for evidence of specific behavior. The $360^{\circ}$ feedback can help achieve this kind of data collection, the process involving large range observation data from the direct superior, same level colleagues, subordinates, and external public. It can be not only based on the self-observations to feedback, also refer to the feedbacks from those with better perspective of the employee (Lucia, Lepsinger, 2004).

4.2.2. Ensure the evaluation system of scientific integrity and coordination consistency

Implementing $360^{\circ}$ feedback based on competency model can be targeted solve: Performance standards blurred and lack of consistency; the evaluation index system of chaos; lack of balance in the evaluation of the achievements and the achievements method. Because this method can let people consensus in evaluation contents, and ensure the balance between the task completion and how to complete. Since competency model shows that an organization is concerned the results, and behavior and ways to get the results of. Competency model makes the leader and direct subordinate to know what behavior and high performance related is important. This model with specific organizational goal together, clearly lists the work performance standards for measuring the success of leaders, and the standard is used to measure $t$ efficiency and the degree of success of the position. At the same time, $360^{\circ}$ feedback will inform the cadres more about others' expectations to his/her performance, which includes the immediate superior, subordinates, and the masses' expectation. Therefore, cadres for the organization to their expectations, there will be less subjective speculation and misunderstanding. Many organizations found 
$360^{\circ}$ feedback can make the organization have accurate and comprehensive understanding to individual performance and let employees know the organization's mission, vision and values, so as to be able to recognize, develop and encourage employees to succeed. Competency model lets employees have a clear understanding of the organization' expectations and how can they succeed.

4.2.3. Emphasize the DAS's feedback and development functions

360 feedback based on competency model can operate with emphasis and promote assessment discussion and evaluation feedback of PGLs. First of all, the feedback system provides a very good chance for the colleagues, superior and subordinate to aloud them providing the real performance information directly related to the person be evaluated and his/her ability in the anonymous and no threat conditions. Many direct supervisor may feel uncomfortable when he/her provides negative feedback; and $360^{\circ}$ feedback would make such feedback very easily. Secondly, the evaluation system can distinguish and descript out the skills, knowledge and individual characteristics which help to succeed. It lets the direct supervisor clearly understand where to conduct discussions, and what should be focused on in the discussion. The system could also help in the evaluation discussion to ensure the clearance and specific of discussion content, and underline the behaviors, distinguishing the individual characteristics and attitude from the skills and knowledge, so as to find points that need to be improved. In addition, the evaluation system helps to make evaluation discussion more clearly, more responsive to questions direct related to work performance, and more easily have a balance between the organizational goals and how to achieve these goals. Moreover, this system is beneficial to the improvement of the performance of self-perception and enhances the promise the person committed to performance improvement. Finally, $360^{\circ}$ feedback system based on competency model can effectively promote the leaders' performance improvement, leadership development and assist leaders' career development.

So, in order to optimize DAS for PGLs, we could try the 360-degree feedback based on competency model system. In other words, the contents designation of DAS can refer the competency model of leaders and the process uses the form of 360-degree feedback.

\section{Conclusions}

Firstly, competency model and 360-degree feedback are two tools and methods both widely used in private and public sectors abroad, they can help to improve DAS of government executives from two aspects as contents and procedure. Secondly, competency model and 360-degree feedback are not simply an issue of technique, the support factors in a certain organization such as good organizational culture and how government executives comprehend the effect of democratic appraisal determine whether the two methods could optimize the DAS effectively. Finally, the results of democratic appraisal should not only apply in selection and evaluation, but also underline the role it plays in government executives' training and developing programs. In other words, extending the DAS's management function to development function could contribute to increase the reliability and validity of DAS as well as bring an active influence on organizational performance improvement.

This study only represents a new perspective and direction to optimize the democratic appraisal system for PGLs. We need further exploration and research on how to improve DAS through building 360-degree feedback based on competency model system which is adapt to national circumstances, to be effective and operable. We have to pay attention that function play of $360^{\circ}$ feedback and competency model depend on many factors, such as organization system, organizational culture, the managers' attitude towards the feedback and the application of the feedback results. Therefore, when we apply these two tools into DAS, we must consider the unique political and organizational backgrounds in China. At last, as with other human resource management and organizational change activities, the top leader group is critical to the implication and function of the new DAS in evaluating and developing PGLs. Only when the top leaders correctly comprehend this system and make a reasonable goal for it meanwhile advocate and carry out the plan personally, it would be more possible to implement the 360-degree feedback based on 
competency model successfully in the process of DAS for PGLs in Chinese public sectors.

Acknowledgment: This paper is financed by The National Social Science Fund Project Human Resource Management in Public Sector: Optimize and Improve Democratic Appraisal System of Chinese Government Executives.

\section{References}

[1] Angelo, S. DeNisi, Avraham, N. Kluger. Feedback Effectiveness: Can 360-degree Appraisals be Improved[J]. Academy of Management Executive, 2000, Vol.14, No.1: 129-139

[2] Anntoinette D. Lucia, Richard Lepsinger. The Art and Science of Competency Models: Pinpointing Critical Success Factors in Organizations[M]. Jossey-Bass/Pfeiffer, 1999: 163-167

[3] Boyatzis, R.E. The Competent Manager: A Model for Effective Performance[M]. New York: Wiley, 1982

[4] Dubois, D.D. \& Rothwell, W.J. Competency-based Human Resource Management[M]. Palo Alto, CA: Davies-Black, 2004

[5] Herman Aguinis. Performance Management[M]. Prentice Hall, 2008: 83

[6] Jai Ghorpade. Managing Five paradoxes of 360-degree Feedback[J]. Academy of Management Executive, 2000, Vol. 14, No.1: 140-150

[7] Liu Xin. Management Development Function of 360-Degree Feedback and Its Implication in Practice[J]. Jianghai Academic Journal, 2009(4): 94-95(In Chinese)

[8] McClelland, D.C. Testing for Competence rather than for Intelligence[J]. American Psychologist, 1973: 1-12

[9] Nitin Vazirani. Competencies and Competency Model: A Brief Overview of its Development and Application[J]. SIES Journal of Management, 2010, Vol. 7(1): 126

[10] Shi Kan. Human Resource Development based on Competency Model[J]. Advances in Psychological Science, 2006, 14(4): 588(In Chinese)

[11] Shipman, J.S. \& Ash, R. A. The Practice of Competency Modeling $[\mathrm{J}]$. Personnel Psychology, 2000: 53
[12] Spencer, L.M \& Spencer, S.M. Competence at Work[M]. New York: Wiley, 1993

[13] Zhuang Guobo. The Theories and Practice of Cadres' Political Performance Appraisal[M]. China Economic Publishing House, 2007: 72-73(In Chinese) 